\title{
TECHNOLOGY AS CULTURAL CAPITAL, PARTICULARLY IN U.S. COLLEGE ACCESS
}

TEXT AND PHOTOGRAPHY BY MARLENA MATTEI

\section{INTRODUCTION}

$\mathrm{D}$ espite efforts to make education more accessible, a college education remains difficult to obtain if one lacks the proper economic and social resources. Further, the inequality in college access between different classes has been documented ${ }^{1}$. Throughout my time volunteering as a graduation coach at a high school in West Philadelphia, I was able to directly observe college access inequalities. I quickly became interested in the 'digital divide' among social classes. My research revealed that not only are there disparities in technology access and knowledge, but that these inequalities can serve as cultural capital in college access.

\section{INTELLECTUAL BACKGROUND}

In the early 1960s, the French sociologist Pierre Bourdieu proposed the concept of cultural capital (the idea that nonfinancial assets can impact social mobility). He argued that cultural behaviour is influential in determining educational success (Bourdieu \& Passeron 1979:14). The theory is general and flexible enough to account for any form of unequally distributed 'competence' that provides advantages to those who have it. Additionally, it is emphasized that these advantages arise from institutionalized standards (Bourdieu 1977a).

Moreover, Bourdieu distinguishes between three subtypes of cultural capital: objectified, embodied, and institutionalized (Bourdieu 1986:47). Objectified cultural capital consists of material items which provide advantages. In order to utilize objectified cultural capital, it is necessary to have prior skill or 'competence.' This knowledge is embodied cultural capital (Kapitzke 2000:51). The embodied form of cultural capital, which can be acquired both consciously and passively, requires an investment of time and energy from the learner. Further, embodied cultural capital can take on an objective value, which could later go on to be advantageous in the labour market. This relates to the third type, institutionalized cultural capital, which occurs when an institution, such as a university or workplace, acknowledges an individual's competencies by formally recognizing skills (Bourdieu 1986). Connected to the types of cultural capital is the concept of habitus, or a set of dispositions gained in response to objective encounters which can affect perceptions and decisions (Bourdieu 1977b).

The broad definition of cultural capital has allowed scholars to expand the concept. Accordingly, the connections between cultural capital and technology have not gone unnoted. Researchers have documented the inequalities between groups in the use of and access to information technology, which is commonly known as the 'digital divide.' Emmison and Frow (1998) introduced the idea of information technology being a variable in cultural capital. They argue that 'a familiarity with, and a positive disposition towards the use of bourgeoisie technologies of the information age can be seen as an additional form of cultural capital bestowing advantage on those families that possess them' (Emmison \& Frow 1998: 44). Emmison and Frow discuss computers as machines, which would be classified as objectified cultural capital, while the knowledge and ability to use these machines form embodied cultural capital (Emmison and Frow 1998:42). More recently, Warschauer (2003) published the findings of global case studies regarding technology and social inclusion. By examining his findings using various theories, including cultural capital, he found that physical access is not the only factor in effectively closing the digital divide. Rather, he argues that access to and the ability to use technology is essential to social inclusion (Warschauer 2003). 


\section{A CASE STUDY}

My research was conducted as participant observation supplemented by informal interviewing, which allowed for a unique perspective into the concept of technology as cultural capital. As an undergraduate studying anthropology, I was interested in secondary education in urban areas. This prompted me to volunteer with a college and career access programme at a high school in West Philadelphia. My emphasis soon became focused on the use of technology by the students and within the organization.

Each Monday for six weeks, I assisted high school seniors with various college and graduation tasks, such as college and financial aid applications. Throughout my time, I worked closely with six African American students (three girls and three boys). As a whole, the student body is mainly made up of African Americans (96.9\%) and economically disadvantaged students (at least 89.3\%) (School District of Philadelphia 2012). Additionally, the average test scores are below that of the School District of Philadelphia's average in both math and reading (School District of Philadelphia 2012).

Granted, six weeks is a relatively short time to fully immerse oneself and understand a certain culture and the problems associated with it. I did not get to work with the same students each week, so I could not develop a lasting relationship, which would surely have provided me with more insight. Additionally, I was working with a very specific age group in a limited environment. Thus, these findings are somewhat generalized. Nevertheless, there are clear patterns that deserve attention and possibly further study on a larger scale.

\section{LACK OF PHYSICAL ACCESS: CREATING THE DIVIDE}

The creation of the divide of technological cultural capital begins with the disparities in access to computers and other technology. Without physical access to technology, assignments and applications must be done differently and research is harder to complete. In these cases computers and other technological machines act as objectified culture, since the lack of access could make it more difficult to achieve ed- ucational success. Further it takes a certain level of knowledge - embodied culture - to be able to operate these machines (as will be discussed later).

\section{At home}

Five of the six students that I worked with did not have computer access in their homes. The main reason that students did not have computers at home seemed to be the expense. The price of a computer, coupled with monthly internet prices, not including various other expenses, such as routers, flash drives, printers, or ink, is relatively large and does not always fit in the family budget. The lack of access proved to be a hindrance for students, as my fieldnotes show:

\begin{abstract}
When we were reading the guidelines for the senior project, it said that the papers needed to be typed. He seemed annoyed and said that this is hard for him because he does not have computer access [at home]... He stated that he usually wrote a rough draft and then typed it up at school.
\end{abstract}

We continued working on his senior research paper I taught him about finding sources and doing work cited pages. This step was very important for him since he does not have access to a computer. It was essential that we used his computer time to the best of our ability. We found one great source, but since we did not have time to take detailed notes, we had to print it out so he could do it at home.

\section{At school}

If students cannot access the internet at home, another option is accessing a computer with internet capabilities at their school. Unfortunately a large portion of the students at this high school did not feel as if there was enough technological availability. Only $52 \%$ of students agreed that the school had enough technological resources (School District of Philadelphia 2010). An unwelcoming environment for technology usage is described in my fieldnotes:

After the presentation, we left the room we were in. [The site coordinator] had to take the projector and two laptops out with her because she was leaving the door unlocked. From the way she talked about the door being unlocked it seemed likely that theft was a consistent problem in the school...

[She] then showed us the room that we would be working in. It was tiny, and filled with test prep 
books, and there were about three laptops. This room was separated from a larger room using a cage like door which also had a lock. I wondered why the door was so intimidating.

Here one can see the precautions taken to protect the devices. This is understandable, as schools are facing extremely limited budgets and must take care of the resources they already have. Nevertheless, the atmosphere that is created because of this is not the most encouraging to students.

\section{At the school library}

At this high school, students could access computers in the school library. One might think this is a simple solution to the problem of access, but using these computers does not just consist of walking into the library and logging on. In fact, both of these steps are difficult at the school.

To access the computers in the library, one must first get to the library. Again, this seems like an obvious statement that is not worth mentioning. However, this task is more difficult than expected. The hallways in the school are not the most pleasant place to be. It seemed as though every time I was in the hallway, I witnessed students being yelled at. My fieldnotes show clear examples of the seemingly exhausting process of walking through the halls to get the library:

On the bottom floor, a male administrator started shouting at a student from across the hallway, because she was supposed to be in detention. It seems like any time the students are in the hallway they are being yelled at. It is like a battleground. She began shouting 'no, no, no' and then ran after the administrator.

Once in the library, there were not many incentives to stay. Rather, the opposite was true. The library had very strict policies:

I saw a small rule sheet outside of the library door. It seemed very strict, even saying that students were not allowed to leave the library to go to the lavatory. I wondered why such a strict and seemingly harsh rule was there.

Once one is in the library and ready to work, there are still obstacles. When working with students, we were unable to log on to and use

\section{Library Rules}

"All Students Must

Follow Library Rules

Ail Students Must Be

In School Uniform

All Students Must Have

A Student I.D, to Enter

The Library...
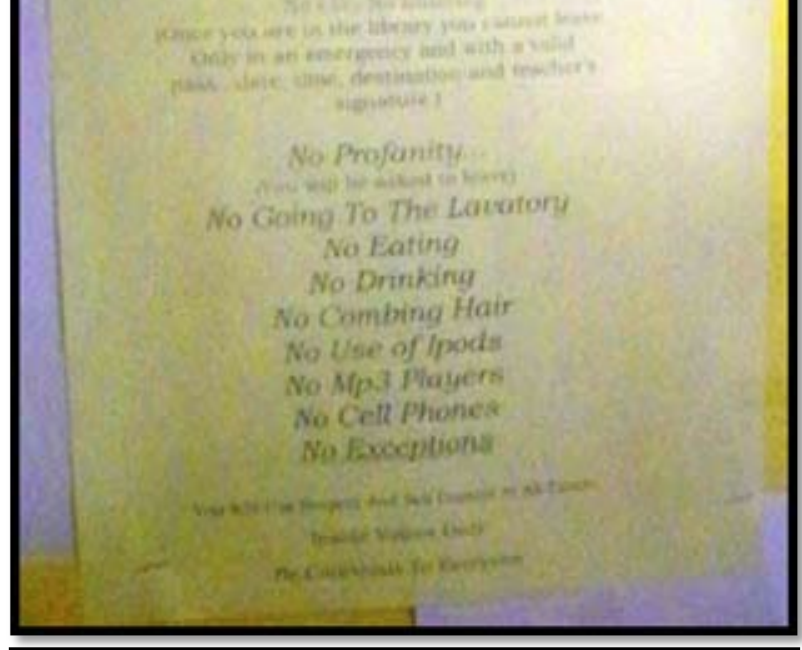

FIGURE 1 A photo of the sign outside of the library. The rules read, 'No Going To The Lavatory' and 'No Exceptions.'

the computers, because the students did not know the password. Additionally, there were no librarians there to provide the password (I later learned the former librarian had been laid off due to budget cuts), nor were there passwords posted:

Finally, we made it into the library. Some of the computers required passwords to log on. The students did not know the passwords and there was not a librarian - or even an adult - in the entire library. I went to see if the password was posted at the front counter. It was not. I thought it was inefficient to have computers the students couldn't access.

\section{LACK OF BASIC KNOWLEDGE: DEMONSTRATING AND MAINTAINING THE DIVIDE}

The lack of access to objectified cultural capital likely creates a divide in the ability to use technology, as students do not have the required experience working with the machines. During my experience, I observed a lack of many basic technological skills. This was noted in my 
field notes on numerous occasions, such as the when students were unable to properly turn off computers nor able to correctly remove flash drives. The most plausible explanation for why students were not properly using the technology is that they did not have the knowledge necessary to do so.

Incidents where students seemed confused and uncomfortable while actively using computer programmes (internet browsers and word processing) and the accompanying accessories (touchpads and keyboards) were observed:

\section{When the student asked for the phone number to the YMCA, she told him to search it on the internet. He minimized each window (mostly word documents) until he reached the 'My Computer' window. He pro- ceeded to try to type his search into the address bar on that page. When it did not work I pointed to the Internet Explorer tab on the toolbar...}

He then typed up his work on Microsoft Word. He apologized for 'being so slow typing.' I told him that he was doing fine and to take his time. This was not the only sign that he felt uncomfortable typing. When he was looking for the comma key he kept pressing the apostrophe key. After he was done copying his written proposal to Word, I looked over it. There were words underlined to signify that they were incorrect. I told him that we should fix those words. He then went in and fixed each on his own. When he arrived at a word he did not know, he asked me how to spell it. He seemed unaware of the suggestions that Word would provide. I told him that if he right-clicked on the word, the programme would show him [suggested corrections]. He began clicking, but not right clicking. I showed him the correct way to do it.

As my fieldnotes show, learning to use technology is not something that one can do instantly. Time must be invested to gain computer skills. In this way, technological knowledge and skills can be seen as embodied culture. Without this embodied culture, students have problems using resources even when they are available to them. Thus, a divide between those with and without technological cultural capital is maintained.

\section{PREFERENCE: A POSSIBLE EXAMPLE OF HABITUS}

Another pattern I observed was the students' apparent preference for using other types of re- sources rather than technological ones:

He seemed to know very little [about his project]. I asked if he had the guidelines. He said he lost it [the guideline sheet]. I asked if it would be posted online, and he said that he did not know and that we needed to ask [the site coordinator]. I thought to myself, we are sitting right in front of the computer. Why not just look [online] and see?...

The group was having a competition to see who could best market TastyKakes. They were discussing various types of marketing placements for ads, such as TV, radio, and newspaper. One girl said she thought it would be useful to give out coupons. I was surprised that no one mentioned how useful internet ads would be, given how prominent it now is in marketing.

Additionally, students often filed for financial aid and applied to colleges using paper applications, rather than completing internet applications, which are usually more efficient and allow for quicker responses. With both my own students and other students, with whom I did not directly work, email addresses were only used if necessary and were often forgotten.

These examples demonstrate a possible preference for using other types of resources and perhaps a lack of knowledge of how useful internet sources can be, both in finding and providing information. The apparent preference for using other types of resources rather than computers and internet can be viewed as a type of habitus. One's disposition and taste are being influenced by embodied culture and helping to form a choice of preference (cf. Bourdieu 1984). It is also important to note that although many types of people view the importance of technology as obvious and undeniable, in this particular case, there did not seem to be the same consensus regarding the significance of technology. In other words, the recognition that technology information can be used as a sort of cultural capital seems to be limited to certain groups.

\section{RESOURCES: WHEN CAPITAL MATTERS}

Today technology surrounds us. To not have the access or ability to use it can be detrimental, especially concerning college preparation. Wikipedia, although not always a reliable source, is incredibly valuable for obtaining knowledge in- 
formally. Websites like Khan Academy, which offer free internet courses, would be a useful supplement to a student who is having trouble in a class or one who is simply curious about a certain topic. My fieldnotes depict students who did not have knowledge of some of these important sites:

\section{When we were discussing locating sources for his senior project, he asked me how he could find them. I recommended Google Search and Google Scholar. I explained the difference between finding a reliable and verified source.}

The student did not seem to have the ability to use the internet to access scholarly articles. Not only would this skill be useful in order to graduate and pursue college, but once he is in college, research is a crucial and an unavoidable aspect of higher education. Four of the students I worked with were unfamiliar with Collegeboard. It was significant that the students I worked with had no prior knowledge of Collegeboard, as it is one of the most important college related sites in the US. It is the website where one registers for the SATs, as well as fills out some financial aid forms. More generally, it can be used to look up common college statistics, in addition to information about majors and careers.

The internet as a general source of information through the usage of search engines was also unrecognized:

The student said that she wanted to become an RN [registered nurse]... and asked what she had to do. I explained that she would be taking a lot of biology classes. She was nervous about taking math classes, so I suggested we research [online] the general classes needed to become a nurse. She seemed surprised that the information could be found this way.

In this particular case the student did not seem to realize that the answers to her questions were literally a few clicks away. Additionally, when she tried to research her question, she had trouble understanding how to use Google to find the information that she needed.

The rapid growth of technology makes it a challenge for many people to stay up-to-date with the latest websites and programmes. The main difference is that students who have nei- ther the basic computer knowledge nor the access to a computer will have a far slimmer chance of learning how to use and take advantage of these valuable resources. This capital will then go on to become institutionalized as colleges and employers select high school students based directly and indirectly on their technological capital.

\section{CONCLUSION}

Based on my research, technology does seem to reflect many of the ideas of Bourdieu's concept of cultural capital, as the lack of physical access, basic knowledge, and usage act as cultural capital when applying to colleges. Without the ability to access and use technology, students have a disadvantage in school and accessing college and careers. This is by no means an easy problem to solve, but there are ways to help equalize this technological gap which could be explored by policy makers. For instance, schools could focus more attention on providing access to technological equipment, preparing teachers to supplement teaching using technological information, and requiring students to take a course in technology usage. 佔

\section{NOTES}

1 For further information on this topic, see Camara \& Schmidt (1999), Lareau (2003), and Mullen (2010). 
Bourdieu, P. (1977a) 'Cultural Reproduction and Social Reproduction.' Power and Ideology in Education 63 (1): 487-511.

Bourdieu, P. (1977b) Outline of a Theory of Practice. Cambridge: Cambridge University Press.

Bourdieu, P. (1984 [1979]) Distinction: A Social Critique of the Judgement of Taste. Translated by Richard Nice. Cambridge: Harvard University Press.

Bourdieu, P. (1986) The Forms of Capital. Handbook of Theory and Research for the Sociology of Education. New York: Greenwood Press

Bourdieu, P. and J. Passeron (1979) The Inheritors: French Students and their Relations to Culture. Chicago: University of Chicago Press.

Camara, W. and A. Schmidt (1999) 'Group differences in standardized testing and social stratification.' College Board Report no. 99-5, New York: College Entrance Examination Board.

Emmison, M. and J. Frow (1998) 'Information Technology as Cultural Capital.' Australian Universities' Review 41 (1): 41-45.

Kapitzke, C. (2000) 'Information Technology as Cultural Capital: Shifting the Boundaries of Power.' Education and Information Technologies 5 (1): 49-62.

Lareau, A. (2003) Unequal Childhoods: Class, Race and Family Life. Berkeley: University of California Press.

Mullen, A. (2010) Degrees of Inequality. Baltimore: Johns Hopkins University Press.

School District of Philadelphia High School Student Survey Report, 2010. Philadelphia: School District of Philadelphia.

School District of Philadelphia School Profile. Electronic document.

https://webapps.philasd.org/school_profile/view/1100, last accessed 9 April 2012.

Warschauer, M. (2003) Technology and Social Inclusion: Rethinking the Digital

Divide. Cambridge: MIT Press. 